\title{
Supply Chain Risk Governance: Towards a Conceptual Multi-Level Framework
}

\author{
Victoria Ahlqvist \\ Department of Industrial Management and Logistics, \\ Lund University Faculty of Engineering, 22100 Lund, Sweden \\ E-mail: victoria.alqvist@tlog.lth.se \\ Andreas Norrman \\ Department of Industrial Management and Logistics, \\ Lund University Faculty of Engineering, 22100 Lund, Sweden \\ E-mail: andreas.norrman@ $@$ tlog.lth.se \\ Marianne Jahre \\ Department of Industrial Management and Logistics, \\ Lund University Faculty of Engineering, 22100 Lund Sweden \\ and \\ Department of Accounting, Auditing and Business Analytics, \\ BI Norwegian Business School, 0484 Oslo, Norway \\ E-mail: marianne.jahre@bi.no
}

\begin{abstract}
The coronavirus pandemic (COVID-19) is currently putting high pressure on most countries' critical infrastructures (not only health care), creating huge uncertainties in supply and demand, and disrupting global supply chains. The global crisis will demonstrate the extent to which different parties (countries, public authorities, private companies etc.) can work together and take holistic decisions in such situations. A core question in supply chain management asks how independent decision-makers at many levels can work together and how this joint work can be governed. Supply chain risk management (SCRM), however, has focused mostly on how focal private companies apply SCRM processes to identify, analyse and mitigate risk related to upstream and downstream flows in their supply networks. At the same time, interorganisational collaboration to handle diverse risks is always needed. A risk that hits one organisation often affects other, interconnected organisations. This study aims to develop the term supply chain risk governance with an associated conceptual framework that embraces various types of supply chains and actors. In a cross-disciplinary literature study, we dissect, compare and combine risk governance with interorganisational aspects of SCRM and find that the mechanisms suggested in the risk governance literature coincide with many of those in SCRM. We suggest a combination of these to govern risk processes at an inter-organisational level, regardless of the type of organisation included in the supply chain. This would be suitable for critical infrastructures that often contain a mixture of private and public actors. The scope of the literature employed is limited, and some articles have played a larger role in the framework development. The paper explores new territory through this cross-disciplinary study, extends existing multi-level frameworks with inter-organisational governance mechanisms and proposes new governance mechanisms to the field. This study could support the understanding of how critical infrastructures in our society are governed so as to increase their resilience to both smaller and larger disruptions.
\end{abstract}

Keywords: risk governance, supply chain risk management, governance mechanisms, critical infrastructure

\section{INTRODUCTION}

When a major incident occurs in today's interconnected society, many organisations will be either impacted by or involved in handling the risk. The current coronavirus pandemic (COVID-19) demonstrates this to an extent hardly ever observed. Putting extremely high pressure on most countries' critical infrastructures, we see that not only healthcare is affected. Ripple effects are hitting almost everything in a modern society including transportation, food, industry, education, and energy. Almost all sectors face huge supply and demand uncertainties. Local, national and global supply chains are disrupted: 'The global supply system collapsed' (DN, 2020). Cooperation and coordination constitute huge challenges, requiring interorganisational risk management. One research domain that deals with this is supply chain management (SCM), in which supply chain risk management (SCRM) has grown in response to firms' increasing need of joint strategies to manage risks. The aim is to ensure business continuity and avoid disruptive events that have costly ripple effects in the supply chain (Fan and Stevenson, 2018; Norrman and Jansson, 2004). SCRM has many definitions focusing on the use of risk management processes in an inter-organisational context, e.g., 'Supply chain risk management is to [collaborate] with partners in a supply chain apply risk management process tools to deal with risks and uncertainties caused by, or impacting on, logistics related activities or resources' (Norrman and Jansson, 2004, p. 436). Friday et al. (2018) argue that, although SCRM definitions contain elements of collaboration, classic risk strategies are limited with regard 
to the means and intensity of collaboration. In SCM, the focus has been mostly on how private companies apply SCRM processes in their attempts to identify, analyse and mitigate risks related to upstream and downstream flows in their supply networks. Suggested mitigation strategies simply transfer the risk upwards or downwards to other actors (Fan and Stevenson, 2018), so the risk remains in the supply chain. The techniques have been criticised for being implemented only at the focal firm level (Friday et al., 2018), one exception being Peck (2005), who suggests a multi-level framework for analysing risk sources and drivers. While based on a system of relationships in inter-organisational networks, logistics flows, assets and infrastructures, Peck's framework does not address how the relationships could or should be managed. To stress the inter-organisational dimension, Friday et al. (2018) define collaborative risk management as 'an interactive process based on mutual commitment between firms with a common objective to join effort and mitigate supply chain risks and related disruptions through co-development of strategic relational capabilities and sharing of resources'. Also, Bak (2018) brings up the importance of understanding supply chain relationships for long-term supply chain risk mitigation and suggests that future research should identify how supply chain members interact and what resources are required.

While SCRM research focuses on private companies and their risks, other domains, such as risk management and societal safety (RMSS) and humanitarian logistics, are more concerned with societal risks and how public or humanitarian organisations deal with emergencies. This relates partly to critical infrastructures, i.e., assets or systems such as electricity, health, transportation and food, in which disruptions would have significant societal impacts. Over time, critical infrastructures have developed from local systems into complex, interconnected, international and integrated systems involving both public and private actors. The risks to which they are exposed are often classified as highly complex (Bekkers and Thaens, 2005; Klinke and Renn, 2012). A breakdown in one system may cause ripple effects and spillovers to others, resulting in catastrophic situations (Bekkers and Thaens, 2005; Ouyang, 2014; Rinaldi, 2001). Due to complex relations, many of these risks cannot be managed by a single actor but require collaboration (IRGC, 2008). What previously was viewed as an intra-organisational task is now characterised by joint tasks in large supply networks of public and private stakeholders who often have competing interests and views on risk. It is therefore important to understand the relationships between such actors as traditional governmental top-down decisions no longer suffice. In response, the concept of risk governance (Arvidsson and Cedergren, 2016; Dubreuil, 2001; Gheorghe et al., 2007; Renn, 2008; Sajeva and Masera, 2006) has emerged in the RMSS domain in cases in which multiple stakeholders are affected by risks and involved in risk management. The purpose is to enable inter-organisational risk evaluation and collective decisions and to handle complex, uncertain and ambiguous risk (Gheorghe et al., 2007; Klinke and Renn, 2012; van Asselt and Renn, 2011; van der Vegt, 2018a).

Governance itself is a construct used in many disciplines, and it has diverse meanings. Broadly, it describes an institutionalised decision-making process among many independent actors. Governance is operationalised into more detailed and concrete governance mechanisms that may direct various actors' behaviours. Similarly, SCM focuses on how decision-makers in long supply chains can work together to jointly manage and govern. To distinguish this inter-organisational dimension from standard risk management, we suggest the term supply chain risk governance. A dilemma from a research point of view is that domains such as SCM and RMSS have studied inter-organisational risk management separately, using different terms such as collaborative SCRM and risk governance, even though both domains developed from systems theory and attempt to describe, understand and handle systemic risk in inter-organisational contexts with multiple decision-makers and potential cascading effects. We argue that it will be easier to design proper governance mechanisms when the underlying similarities and differences in backgrounds and perspectives are understood.

This study aims to develop the term supply chain risk governance with an associated conceptual framework that embraces diverse types of supply chains and involved actors by dissecting, comparing and combining risk governance with the inter-organisational aspects of SCRM. The study offers a multi-level analytical framework incorporating various mechanisms for inter-organisational governance related to SCRM, which contributes to previously suggested multi-level frameworks (Peck, 2005) both by adding explicit risk governance mechanisms and by taking a crossdisciplinary approach in combining the domains of SCM and RMSS. We do this by reviewing the relevant literature and, in the next section, presenting the methodology used. We then describe the two domains (SCM and RMSS), followed by a comparison of their key dimensions and characteristics. Section 4 develops the framework, and the final section summarises the conclusions and limitations and suggests areas for future research.

\subsection{Research Process}

\section{METHODOLOGY}

To compare the constructs risk governance and collaborative SCRM, the current state of understanding in the two research domains (SCM and RMSS) must be examined. Following the recommendation of Rowley and Slack (2004), this paper employs the literature review as a scoping study in line with suggestions by Arksey and O'Malley (2005) and Davis et al. (2009). At a general level, such scoping studies 'aim to map rapidly the key concepts underpinning a research area and the main sources and types of evidence available, and can be undertaken as stand-alone projects in their own right, especially where an area is complex or has not been reviewed comprehensively before' (Mays et al., 2001, p. 194). Often performed in an iterative way, a scoping study comprises the following steps: (1) identifying the research question; (2) identifying relevant studies; (3) selecting studies; (4) charting the data; (5) collating, summarising and reporting the results. To enable a structured analysis, our literature review was combined with content analysis following Seuring and Gold's (2012) fourstep model of qualitative content analysis: (1) determining the material to analyse and the unit of analysis, i.e., scoping the study; (2) assessing formal characteristics through a descriptive analysis; (3) selecting categories for analysis; (4) 
analysing the material. Some of these steps overlap; the combined procedure is illustrated in Figure 1.

The initial literature recommended by scholars helped to formulate the research questions and define our unit of analysis (the governance of inter-organisational risk management in supply chains, which we call supply chain risk governance). In the next step, the literature was retrieved through keyword searches, scholar recommendations and snowballing, resulting in 33 and 26 papers in risk governance and SCRM, respectively. The remaining steps constituted the analysis. Steps 1 to 3 were performed linearly, but an iterative process was needed between steps 4 and 5 to shape the categories for analysis. Step 5 involved separate but parallel content analysis of the respective constructs, which were summarised and compared in step 6 .

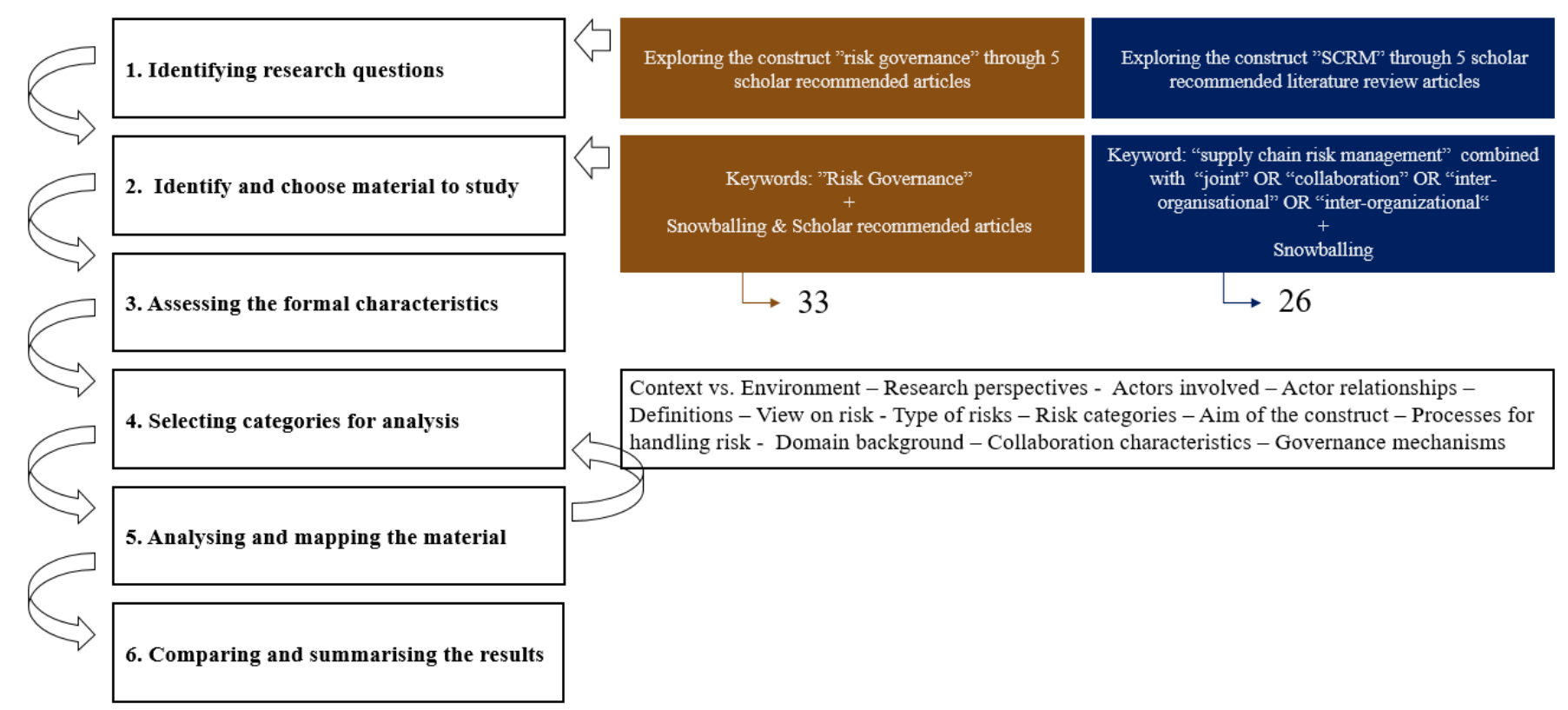

Figure 1 Outline of the research process

\subsection{Exploring the Constructs and Defining the Study}

To explore the constructs and their potential overlap, scholars in each research domain were asked to recommend relevant central articles. Many SCRM literature reviews have been published in recent years. Therefore, literature review articles were chosen exclusively in that construct to provide a good overview of the research frontier. Keyword searches were used to explore the breadth of existing work on each construct. These procedures confirmed the relevance of the study, defined the unit of analysis and formed the research questions. As the unit of analysis (supply chain risk governance) is differently termed in each domain, the units we analyse are the relevant terms for the governance of interorganisational risk management. The following research questions were formulated:

RQ1: What are the differences and similarities between SCRM and risk governance?

RQ2: What are the respective constructs' views on the interorganisational aspects of risk management?

RQ3: How can supply chain risk governance be characterised?

\subsection{Material Selection}

Keyword searches restricted to peer reviewed articles in academic journals were performed in the EBSCOhost database. The search term risk governance was used to search for papers on risk governance in the following journals: Risk Research, Risk Analysis: An International Journal and European Journal of Risk Regulation. We selected the journals through an iterative process in consideration of their status as the leading journals in the domain (according to researchers in RMSS) and because they had the greatest number of articles on the subject in the database. The search yielded 80 articles. To identify key papers on SCRM, the term supply chain risk management was combined with the additional keywords: joint, collaboration, inter-organisational and interorganizational, in four separate searches and 37 articles were found.

To assess the relevance of the articles, the titles, keywords and, in some cases, abstracts were screened, yielding 21 papers on risk governance for analysis. To ensure that no important or key papers in the field were neglected, scholars in the domain were asked to suggest articles that they deemed relevant. This, in combination with citation pearl-growing/snowballing to capture frequently cited articles, yielded an additional 12 articles. In total, 33 articles were used for the content analysis of risk governance (Table 1). The 37 articles identified on the SCRM construct were screened in a similar manner and two papers were also excluded during the full paper review. The remaining set of articles were combined with previously read literature review articles and articles retrieved through citation pearlgrowing/snowballing, leaving 26 articles for the final analysis. 
Table 1 Articles read and analysed in the study

\begin{tabular}{|c|c|c|c|}
\hline \multicolumn{2}{|c|}{ Risk governance literature } & \multicolumn{2}{|l|}{ Supply chain literature } \\
\hline Arvidsson \& Cedergren & 2016 & Bak & 2018 \\
\hline Aven & 2011 & Cantor et al. & 2014 \\
\hline Bekkers \& Thaens & 2005 & Cao et al. & 2010 \\
\hline Boholm \& Corvellec & 2011 & Chen et al. & 2013 \\
\hline Boholm et al. & 2012 & Cruz \& Liu & 2011 \\
\hline Brown \& Osborne & 2013 & Fan \& Stevenson & 2018 \\
\hline Cedergren \& Tehler & 2014 & Friday et al. & 2018 \\
\hline de Vries et al. & 2011 & Ghadge et al. & 2017 \\
\hline Dubreuil & 2001 & Govindan \& Chaudhuri & 2016 \\
\hline Dubreuil et al. & 2002 & Grötsch et al. & 2013 \\
\hline $\begin{array}{l}\text { Escuder-Bueno \& } \\
\text { Halpin }\end{array}$ & 2018 & Ho et al. & 2015 \\
\hline Florin & 2013 & Kache \& Seuring & 2014 \\
\hline Gheorge et al. & 2007 & Kilubi \& Rogers & 2018 \\
\hline Hanssen et al. & 2018 & Lavastre et al. & 2012 \\
\hline Klinke \& Renn & 2012 & Lavastre et al. & 2014 \\
\hline Lansink et al. & 2018 & Li et al. & 2015 \\
\hline Lindoe \& Kringen & 2015 & Manuj \& Mentzer & 2008 \\
\hline Lindskog \& Sjödin & 2016 & Norman \& Jansson & 2004 \\
\hline Lindskog et al. & 2011 & Ojala \& Hallikas & 2005 \\
\hline Renn & 2008 & Revilla \& Saenz & 2017 \\
\hline Renn et al. & 2011 & Urciuoli et al. & 2014 \\
\hline Rooderijs et al. & 2014 & Wieland \& Wallenberg & 2013 \\
\hline Rübing & 2012 & Zeng \& Yen & 2017 \\
\hline Sajeva \& Masera & 2006 & Zhu et al. & 2016 \\
\hline Stone et al. & 2018 & & \\
\hline Tehler & 2012 & & \\
\hline van Asselt \& Renn & 2011 & & \\
\hline van Asselt \& Van Bree & 2011 & & \\
\hline van Asselt et al. & 2015 & & \\
\hline van der Vegt & $2018 a$ & & \\
\hline van der Vegt & $2018 b$ & & \\
\hline Wachinger et al. & 2013 & & \\
\hline Wong & 2015 & & \\
\hline
\end{tabular}

\subsection{Studying and Analysing the Material}

The following preliminary categories were set when exploring the two constructs in the initial step of this study:

- Year of publication

- Journal of publication

- Research methodology

- Purpose of the study

- Unit of analysis

- Type of industry or organisation in focus

These were mapped to identify potential patterns and to provide a background for the content analysis. Initial categories for content analysis were also established. These were kept broad and unspecific to ensure that nothing was overlooked. A selection of the articles was then read in full to add new categories and divide existing categories into subcategories. Figure 1 depicts the full set. Deriving the categories to be used in the literature review from the literature itself is often required to increase openness to new input (Rowley and Slack, 2004). Thus, the sub-categories were derived inductively by studying the literature in both domains.

The material was read a second time with a focus on coding the categories. The content analysis had two foci. First, we searched for key characteristics to better understand the context of the two constructs and their comparability, enabling us to deduct the differences identified when comparing categories related to relationship interfaces and activities. Second, we described each domain's understanding of inter-organisational mechanisms and activities to manage risk.

The two constructs were initially analysed separately to summarise their views on the respective categories. Afterwards, the categories were systematically compared in terms of both their overriding key characteristics and their operational governance mechanisms before being synthesised in the framework.

\section{LITERATURE}

\subsection{From Governance to Supply Chain Governance Mechanisms}

Governance refers to all processes of governing, whether conducted by a government, a market or a network of organisations (Bevir, 2012). The existing literature uses the governance construct in very diverse ways. It may focus on a particular governance level associated with a type of organisation (such as public, global, nonprofit, corporate and project governance) or a specific field of governance associated with an activity or outcome (such as environmental or information technology). Governance is discussed in a broad range of theoretical domains, including political science, public administration, economics and corporate strategy.

Governance in general relates to 'the processes of interaction and decision-making among the actors involved in a collective problem that lead to the creation, reinforcement, or reproduction of social norms and institutions' (Hufty, 2011). The most formal governing body is a government that makes binding decisions in a given geopolitical system by establishing laws. Governance also refers to social systems, such as families, tribes, territories and formal or informal organisations. Governance may be conducted through the laws, norms, power or language of an organised society (Bevir, 2012). In business and supply chain relationships, governance may be built into relational contracts that foster long-term collaboration and innovation. In business, much attention has been directed at corporate governance theory, influencing research in a wide variety of disciplines (Keasey et al., 2005), which is broadly viewed as how firms should be governed to run effectively and efficiently (Strange et al., 2009).

The governance of inter-organisational relationships has received considerable attention from a variety of theoretical perspectives, e.g., new institutional economics 
literature (including transaction cost analysis) (Wathne and Heide, 2004), strategy, marketing and SCM. The degree of formality of governance depends on the internal rules of a given organisation and, externally, on those shared with its business partners.

Governance is often distinguished from governance mechanisms. While governance is a higher-level construct describing an organisational construction or, in broader terms, institutional framework, governance mechanisms are the underlying and concrete management and control activities. Governance mechanisms describe in detail how the required behaviour of the organisation will be motivated, influenced and established. They are thus more 'administrative tool[s]' (Martinez and Jarillo, 1989). A governance mechanism represents an actual operative practice between the parties. Obviously, the two constructs are related; governance is supported by governance mechanisms that allow companies to solve the problems of safeguarding, cooperation and coordination (Hoetker and Mellewigt, 2009).

In the context of inter-organisational relationships, two common approaches to achieving coordination are discussed: formal governance mechanisms and relational governance mechanisms (Dekker, 2004; Martinez and Jarillo, 1989; Poppo and Zenger, 2002). Formal mechanisms are generally understood to include 'depersonalised exchanges, a reliance on financial parameters, and the drafting and implementation of formal contracts' (Ferguson et al., 2005, p. 217). Relational governance mechanisms, on the other hand, are generally understood to include peopleor social-based mechanisms that enhance open communication and the sharing of information, trust, dependence and cooperation (Eisenhardt, 1985). Unfortunately, the precise terminology of governance mechanisms varies considerably, reflecting the range of scholars studying the topic (Hoetker and Mellewigt, 2009). In their empirical study, Hoetker and Mellewigt (2009) contribute by describing formal governance mechanisms that specify each party's role, performance expectations and dispute resolution mechanisms, such as business plans, service level agreements, prices and performance indices as well as ways of monitoring the partners, such as profit and loss accounts, economic efficiency calculations and reporting requirements. Further, they provide examples of relational governance mechanisms, such as: establishing teams, task forces and committees; direct managerial contact through trips, meetings, and even the transfer of managers; mechanisms for shared decision-making; and formal systems for conflict resolution that rely on two-way communication and joint problem-solving. These relational governance mechanisms mitigate potential opportunism by building trust and social identification.

Although inter-organisational coordination between distinct actors in supply chains (or networks) is one of the key ideas of SCM, the SCM domain does not often use the term governance. Among the few who use the term, Ghosh and Fedorowics (2008, p. 454) define (and explain) supply chain governance as 'a number of critical relationships [that] must be in place between sets of chain members (partners). Partners in the chain must agree on a common governance structure that will direct their relationship and reduce the threat of opportunism in an exchange. Governance is the structure that ensures that decisions are made that lead to long-term, sustainable value for an entity such as a corporation or, in this case, a formal collaboration between multiple organisations. Governance mechanisms must be designed to accommodate potential conflicting goals of independent members' (p. 454). Mechanisms and activities to manage, control and coordinate inter-organisational relations, however, are often discussed and termed differently. Influenced by organisational economics theories (e.g., agency theory and transaction cost economics), Simatupang and Sridharan (2005) provide a framework of inter-organisational interface variables (or antidotes) that should support SCM and coordination. They argue that mutual strategic objectives, appropriate performance measurement, synchronised decision-making, information sharing and incentive alignment (Figure 2) will lead to more streamlined business processes between organisations. At a high level, this model includes both formal mechanisms (goals and objectives, performance measures and incentive alignment including contracts) and relational mechanisms (decision-making, information sharing).

SC Interface variables/ antidotes

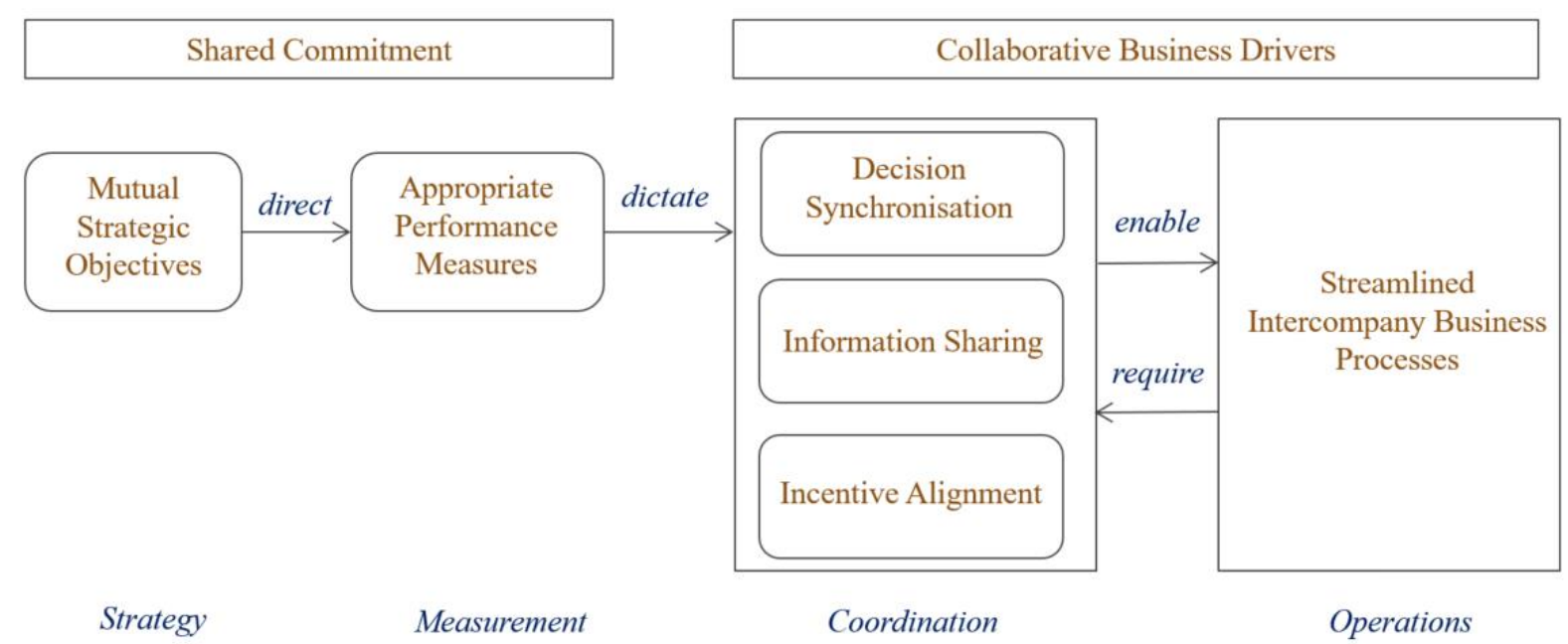

Figure 2 Inter-organisational interface variables to prevent supply chain discontent (Simatupang and Sridharan, 2005, p. 357). 


\subsection{Overriding Key Characteristics of the Governance Context}

Our initial screening and comparison of the two constructs identified similarities and differences in the key characteristics and governance contexts they address (Table 2). First, the context addressed and the perspective taken are broader and more inclusive in the RMSS domain, which discusses risk governance, compared to SCRM. This difference seems to explain many others identified in our analysis. With its societal focus, risk governance includes a greater variety of actors, such as public agencies, private companies and others. On the other hand, SCRM, which primarily focuses on the risks in private companies' supply chains, views the surrounding societal and public environment as containing external risks that organisations cannot control. Whether the context determines the perspective or vice versa is not clear. What we can conclude is that risk governance considers societies' and policy- makers' perspectives on how to handle risk while, in SCRM, risk mitigation strategies and processes are formed with a focal private firm's perspective in mind.

The aim of both domains can be deduced from their distinct perspectives. In risk governance, achieving public safety and compliance (Stone et al., 2018) is viewed as success. The aim is to efficiently create and implement policy and regulations to reduce risk and create public safety and trust. In SCRM, business continuity are often mentioned as key success factors (Fan and Stevenson, 2018; Zhu et al., 2017). This, combined with financial performance and customer satisfaction, seem to be the primary goals while public safety comes second. Simultaneously, governmental policies and legal restrictions are often judged as external risks (Manuj and Mentzer, 2008). Interestingly, matters seen in risk governance as restraints (finance) are an aim in SCRM and vice versa (see Table 2).

Table 2 Comparison of the constructs' backgrounds and perspectives

\begin{tabular}{lll}
\hline Key Characteristics & \multicolumn{1}{c}{ Risk Governance } & \multicolumn{1}{c}{ Collaborative SCRM } \\
\hline Context & $\begin{array}{l}\text { Public agencies \& private companies, society, global } \\
\text { systems }\end{array}$ & Private companies, global system \\
\hline Perspective & Society \& Policy makers & Focal firm \\
\hline Aim & Public safety, trust \& compliance (finance constraint) & $\begin{array}{l}\text { Financial results \& customer } \\
\text { satisfaction first, (public safety later) }\end{array}$ \\
\hline Actors & Governmental agencies, Public sector, Civil society (the & $\begin{array}{l}\text { Supply chain actors (mainly private } \\
\text { sector) }\end{array}$ \\
\hline Relationship & Mublic), Scientists, Private sector, NGOs etc. & $\begin{array}{l}\text { More based on supply chain } \\
\text { transitions }\end{array}$ \\
\hline Focused risks & Systemic risk affecting society & Business risks \\
\hline View on risk & Perception + Probability $\times$ Impact & Probability $\times$ Impact \\
\hline Risk categories & Risk sources are analyzed differently dependent on & $\begin{array}{l}\text { More instrumental analysis of risk } \\
\text { sources }\end{array}$ \\
\hline Ambition & known risk uncertainty & Normative, mutual commitment, \\
& Descriptive \& Normative, Joint approach, Collaborative & strategic relationship \\
\hline Design of Risk & relationship & $\begin{array}{l}\text { Instrumental application of a } \\
\text { traditional RM-process }\end{array}$ \\
Management & Application of RM-process based on pre-estimation of \\
Process & actor's value \& risk characteristics & When there is a high level of \\
\hline Applied & & interdependencies in the SC \\
\hline
\end{tabular}

Another difference, shown in Table 2, is the actors involved in the risk management process. Risk governance embraces more stakeholders than does SCRM. In risk governance, there is consensus that various types of stakeholders must be involved to address the interconnections between parties and in light of the impact of diverse values and perspectives on the success of the management strategy (Arvidsson and Cedergren, 2016; Gheorghe et al., 2007; Klinke and Renn, 2012; Renn, 2008). Depending on the type of risk, various types of stakeholders, e.g., scientists, the private sector, civil society, the public and governmental agencies, must be involved in the process. In SCRM, the focus is on the supply chain actors that are directly involved in physical flows, typically private companies.

Further, what constitutes an inter-organisational relationship differs, as actors' relationships are dictated by different means in the domains (Table 2). While we find that relationships in risk governance are based more on policies, legal frames or public trust, SCRM focuses on relationships between the actors partaking in such activities as transactions and the flow of goods (Lavastre et al., 2014).

The type of risk emphasised is also different. While risk governance is concerned with systemic risk, defined as risk threatening crucial societal systems (Aven, 2011), SCRM focuses on the risks impacting a company's logistics flows and resources. A key difference seems to be the view of risk 
and how it is defined. In risk governance, it is commonly considered that risk is socially constructed (Brown and Osborne, 2013; Klinke and Renn, 2012; Renn, 2008; Sajeva and Masera, 2006) but that it can be scientifically defined and calculated when uncertainty and complexity are reduced. Hence, this view follows recent risk research in which the lines between subjective and objective types of risk are blurred and depend on risk uncertainty and complexity. This subsequently influences how the risk management process is designed. SCRM uses both (Tse et al. 2018), with focus on the engineering approach, the more traditional, typical for the oil industry, assuming risk to be objective and measurable. The social science approach, on the other hand, assumes that where people are involved, as in supply chains, objective and perceived risk become inseparable (Mangan and Lalwani, 2016), and has more recently picked up in SCRM research and practice. Amor and Ghorbel (2018) exemplifies the first, Adeseun et al. (2018) the latter.

The differing definitions of risk influence how risk sources are categorised (Table 2), which in turn influences how risk is handled, e.g., mitigated. The risk categories mentioned in the risk governance literature depend on the amount and type of uncertainty associated with the risk. Van Asselt and Renn (2011, p. 432) define risk governance as 'the various ways in which many actors, individuals, and institutions, public and private, deal with risks surrounded by uncertainty, complexity, and/or ambiguity'. Such distinct contextual characteristics (uncertainty, complexity and ambiguity) have impacted the main framework (International risk governance council, IRGC) on how to govern risks depending on the type of risk (Renn, 2008). Van Asselt and Renn's (2011) classification has been criticised for not accounting for the evolving nature of risk (de Vries, 2011). SCRM literature, on the other hand, often classifies risk sources based on their origin in relation to the material flow, e.g., supply, demand, operations, internal, network, external and so on (Jüttner et al., 2003; Manuj and Mentzer, 2008). Similarly, the mitigation strategies chosen for a given risk will often be associated with its origin.

Both domains have the ambition of providing normative advice. Risk governance, as clearly demonstrated in its definition, wishes to be both descriptive (studying interacting networks that are executing risk decisions) and normative (advising societal actors on how to deal with risk) (van Asselt and Renn, 2011). This deviates to some extent from SCRM, which aims to implement actions and thus represents a normative research field (Lavastre et al., 2014).

There are clear similarities in how the risk management process is designed in each domain. Both are based on the traditional risk management process, normally divided into three to six steps, including risk identification, assessment, mitigation and monitoring. Although the representation of the process and each step's definition may differ, the main attributes are consistent. Even though the suggested risk management processes in both domains are based on identical ideas, several differences are apparent. In the risk governance process, the term risk perception plays a much bigger role, probably because risk is considered to be socially constructed. Thus, added to the classical risk management process is a pre-assessment state that aims to clarify how the stakeholders' different perceptions of risk and the context (e.g., social, legal, economic) will influence and restrain the risk assessment through bias (Renn, 2008). The risk perceptions thus determine which actors to involve, what knowledge to retrieve and what organisations should be responsible for risk mitigation. SCRM takes a more instrumental approach to the risk management process to proactively manage risk. Some authors include risk monitoring (e.g., Ho et al., 2015; Norrman and Jansson, 2004) as a key step while others do not (e.g., Manuj and Mentzer, 2008). Also, reactive SCRM processes are discussed (e.g., by Grötsch et al., 2013). Lavastre et al. (2014), however, propose a deviating model that focuses on understanding rather than on implementing action. Their identification phase is replaced by a less restrained riskperception phase. While rare in SCRM, this is far more common in risk governance. Debatable risk perception may have influenced the development of SCRM, which deals with risk across organisations whose actors may have different views on risk sources and events. However, this seems not to influence how risk is addressed; once a risk is identified, a more straightforward application of a traditional risk management process is implemented in SCRM. This lack of more customised processes for different risk types and underlying values is the main difference between the two domains.

Finally, the two constructs are both applied in an interorganisational context in which interconnections and interdependencies increasingly complicate how the organisations manage their individual risk management processes. The more that public and private organisations are part of the same supply chains, the more important it will be to find governance mechanisms to improve coordination and collaboration across sectors and disciplines. Our claim is that it will be easier to design proper governance mechanisms when the underlying similarities and differences in backgrounds and perspectives are understood.

\subsection{Governance Mechanisms}

To identify the prerequisites of supply chain risk governance, the study focused on identifying which are the aspects that the respective domains claim will facilitate the inter-organisational governance of SCRM processes. By studying the two domains and constructs, we established that multiple variables influence the interface between organisations (see Figure 3). However, neither domain presents a homogenous picture of how to design interorganisational risk management strategies. To compare the two and aggregate all the discussed aspects, we distinguish between their perspectives on: (1) who is involved in the interface, (2) what overall approach guides the collaboration, (3) what processes should be governed and, finally, (4) what mechanisms influence inter-organisational collaboration. 
Risk Governance

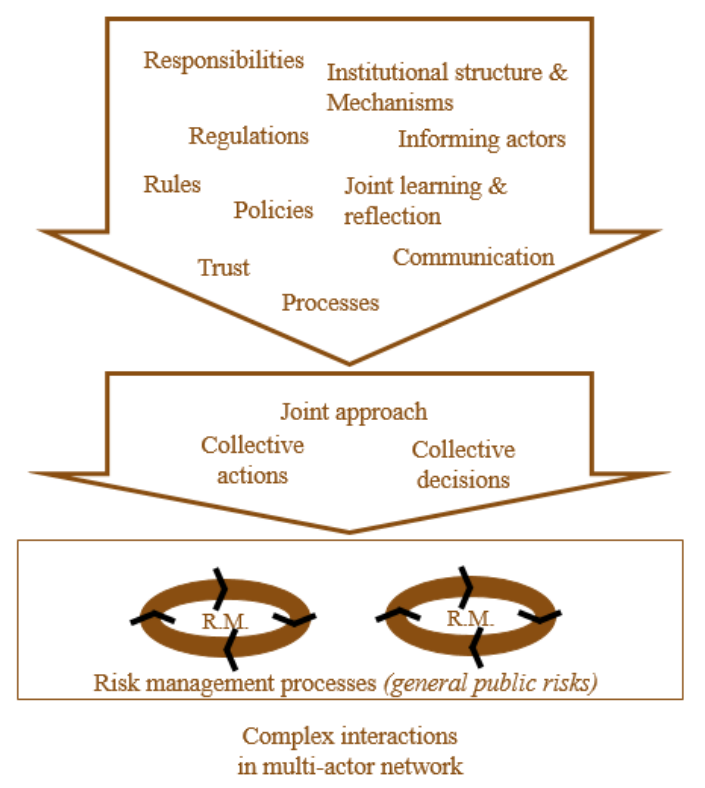

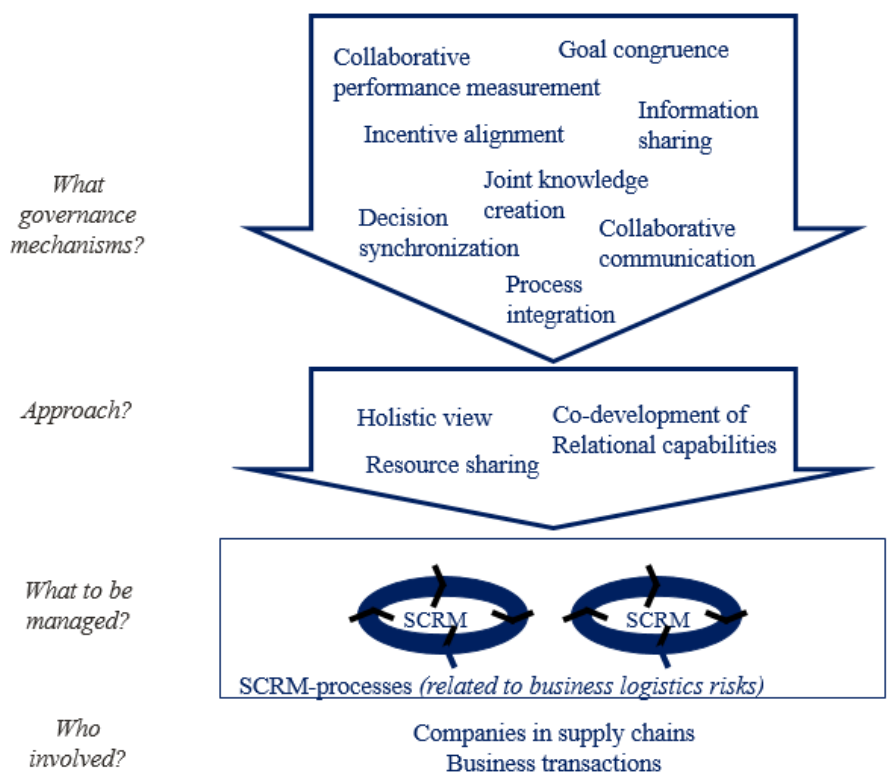

Collaborative SCRM

Figure 3 Comparison of governance mechanisms/interface variables

While both domains deal with complex interorganisational systems of multiple actors, the types of actors that their constructs have in focus differ today (society and the public vs. private companies in supply chains) (see Table 2) but grow increasingly similar. These actors are also the ones expected to be involved in the collaboration.

The focused goal for governance comprises the interorganisational risk management processes. As discussed in section 3.2, the risk management processes are quite similar in terms of steps and concrete activities but differ in risk type and scope. The risk governance construct aims to implement a joint risk management process while the SCRM literature discusses how to integrate and align individual SCRM processes.

The risk governance literature highlights the need for a joint approach (Sajeva and Masera, 2006), collective activities to handle risks (Klinke and Renn, 2012) and collective decisions (van der Vegt, 2018a). These collective decisions are encouraged through policy so that no individual stakeholder is prioritised (Klinke and Renn, 2012; Sajeva and Masera, 2006). The SCRM literature also insists on the need for some collaboration as soon as a business transaction exists between two stakeholders. Increasing attention is directed at joint efforts through resource sharing and joint development of relational capabilities to mitigate risks so as to address them from a more holistic perspective.

When it comes to interface variables and governance mechanisms, we find both similarities and differences. Many differences can be explained by the domains' inherent perspectives (Table 2). The societal perspective of risk governance highlights the role of institutional structures and mechanisms while SCRM relies on formal and relational mechanisms that are collaboratively developed between business partners. The governance mechanisms (Figure 3) observed in the risk governance literature vary, and definitions of the construct often incorporate policies, rules and processes. Van Asselt and Renn (2011) argue that three principles dictate how risk governance is pursued, the first being communication and inclusion, which is understood as joint approaches in our conceptual framework (Figure 4). This provides a joint basis for governing risks, meaning that all relevant stakeholders should be included in the entire risk governance process with communication between the actors to increase their understanding and trust. However, guided by the context, the degree of inclusion will vary. The second principle is integration, which looks back to the underlying view of risk in risk governance. It highlights the importance of having values and concerns affecting risk perception that complement the scientific knowledge. Further, it stresses the integration of the various steps in the risk governance model to prevent information loss. Finally, the principle of reflection should prevent repetition through the actors' jointly reflecting upon and learning from previous experiences. Learning, both from one's own experiences and those of others, is a recurring feature of risk governance. One should be open to communication between risk managers, scientific experts and the public to learn from one another (Lindskog and Sjödin, 2016; Renn, 2008) and to jointly create knowledge (van Asselt and Renn, 2011). Boholm et al. (2012) propose trust, legitimacy, a personal network and a sense of responsibility as key attributes of successful governance. Dubreuil et al. (2002) also mention the need for trust and responsibility assumed by the involved actors as well as the need for informal and formal networks to facilitate the interactions between actors.

Six capabilities are frequently mentioned in the SCRM literature as key enablers of inter-organisational action against risk: information sharing, standardisation of procedures, decision synchronisation, incentive alignment, supply chain process integration and collaborative performance systems (Friday et al., 2018, inspired by Simatupang and Sridharan, 2005). These collaborative mechanisms can take many forms, often related to information, resource and risk sharing and congruous goals. Important elements include the integration of relational and strategic information (Zhu et al., 2017) and communication and cooperative competencies (Wieland and Wallenberg, 2013). Wieland and Wallenberg (2013) note that 
communication will affect a system's agility as well as its robustness by minimising information asymmetry. Instead of policies and rules dictating the premises of the interface, mutually agreeable incentive alignment, contracts and collaborative performance systems are used (Friday et al., 2018; Norrman and Naslund, 2019; Norrman and Jansson, 2004). Norrman and Jansson (2004) cite the example of how Ericsson tried to spread its SCRM approach through its supply chain both by sharing knowledge and training suppliers as well as through formal contract requirements on how suppliers should work with SCRM and set requirements for their own suppliers. Collaborative relationships deviate from more transactional ones through their increased focus on joint knowledge creation (Cao et al., 2010). Cao et al. (2010) shed light on the fact that collaborative communication is often set aside despite its importance. Lavastre et al. (2014) discuss the importance of interorganisational relationship characteristics and state that formalised relationships can reduce ambiguity. However, there is limited research to date on the joint governance of distinct companies' risk management processes. Policies and regulations will, of course, also have an influence. The difference between the constructs is that SCRM views policies and regulations as external constraints and risk sources in themselves because they are determined by the surrounding environment and are therefore seen as noncontrollable from the private actor perspective. SCRM seems to go deeper than the risk governance literature into interface variables in operations, such as standardisation of procedures to minimise variation and ensure the continuity of collaborative risk management agreements (Friday et al., 2018). Process integration is also seen as a tool used to reduce variability by eliminating process variations and stock outs (Friday et al., 2018).

Finally, both domains mention collaborative decisionmaking. However, SCRM views it as a variable affecting the outcome of inter-organisational risk management (e.g., through limiting spill-over effects) rather than as a part of the overall approach (Friday et al., 2018).

\section{TOWARDS A CONCEPTUAL FRAMEWORK}

Based on the analysis above, this chapter presents a conceptual framework for supply chain risk governance. Our multi-level framework (Figure 4) has three layers and combines the structures of Peck (2005) and Simatupang and Sridharan (2005). To simplify, Peck's (2005) four levels are combined in our bottom level, illustrating the supply chain flows where risks must be managed to avoid disruption (e.g., those related to critical infrastructures, emergency flows or fashion industry flows). Hence, actors may be public organisations or private companies-normally a combination-connected to the supply chain in various ways. They can be physically related to the critical flows directly or indirectly, as in the case of institutions that create platforms for interactions (e.g., industry and trade associations) and organisations that intervene through policies and decisions (e.g., various authorities at the sector, regional and local levels). To understand which actors are directly and indirectly involved in the supply chains (in normal situations as well as in times of crisis), the starting point is to map and understand this 'ultimate supply chain'
(Mentzer et al., 2001) of flows, actors, resources and activities at a high level. This mapping and understanding of the network structure and physical flows will help to identify who is involved (or should be involved) in the operative SCRM processes and in their inter-organisational coordination and governance.

The risk management processes themselves are part of the second level and may be used separately by diverse actors, both public and private. While the framework does not describe or develop those processes, it highlights that they should be better governed inter-organisationally. As discussed in both domains, there is an increased need for collaboration when managing risks in an interconnected supply chain. The focus of the multi-level framework is the upper level, which operationalises the supply chain risk governance structure into distinct mechanisms and interface variables. These mechanisms should, in turn, facilitate and encourage inter-organisational SCRM. This upper layer is influenced by Simatupang and Sridharan's (2005) SCM framework, and we propose that the governance structure will improve the coordination of separate risk management and SCRM processes.

Although the framework aims to be useful to various kinds of complex, multi-actor supply chains (containing only private actors, only public actors or a mix), this paper's context relates to critical infrastructures or emergency supply chains containing a mix of private (coloured blue in Figure 4) and public actors (coloured brown in Figure 4). While we found different supply chain risk governance elements suggested in the SCM literature (blue frames) and in the risk governance literature (brown frames), the majority overlapped. In general, we found that the risk governance literature focuses more on societal elements at a higher level while the SCRM literature focuses more sharply on operational mechanisms for process integration. However, many of the suggested governance mechanisms are common although different terms may be used.

We identified three formal governance mechanisms, two of which (strategic alignment and collaborative performance measurement systems) aim to ensure a shared commitment between the supply chain actors. Firstly, it seems important to understand whether and how the SCRM processes are aligned to other important elements in the context. This may be alignment to other strategies (public authorities' as well as private firms' strategic goals), to other stakeholders' values or to society, political ambitions, ethical and legal issues and so on (Cao et al., 20109; Manuj and Mentzer, 2008; Sajeva and Masera, 2006; van Asselt and Renn, 2011). While the two domains both find strategic alignment important, what should be aligned differs. The second formal mechanism-collaborative performance measurement systems - follows from the strategic intentions (Friday et al., 2018; Simatupang and Sridharan, 2005). These could have various purposes, for example, to drive collaboration as well as to monitor and drive behaviour so that it aligns with existing strategies. Whether and how joint key performance indicators are developed, implemented, and used between actors should be understood. If these two formal governance mechanisms support various actors in aiming at shared commitment, the remaining formal governance mechanism aims to increase collaboration and coordination (Simatupang and Sridharan, 2005). This may be understood as the set of formal governance mechanisms 
that we have clustered in the model under the term interorganisational institutional mechanisms. Legal frameworks, policies and contracts (Dubreuil, 2001; Fan and Stevenson, 2018; Renn, 2008; Urciuoli et al., 2014), for example, are tools that assist in defining accountability and responsibility as well as aligning incentives and creating goal congruence among the actors.

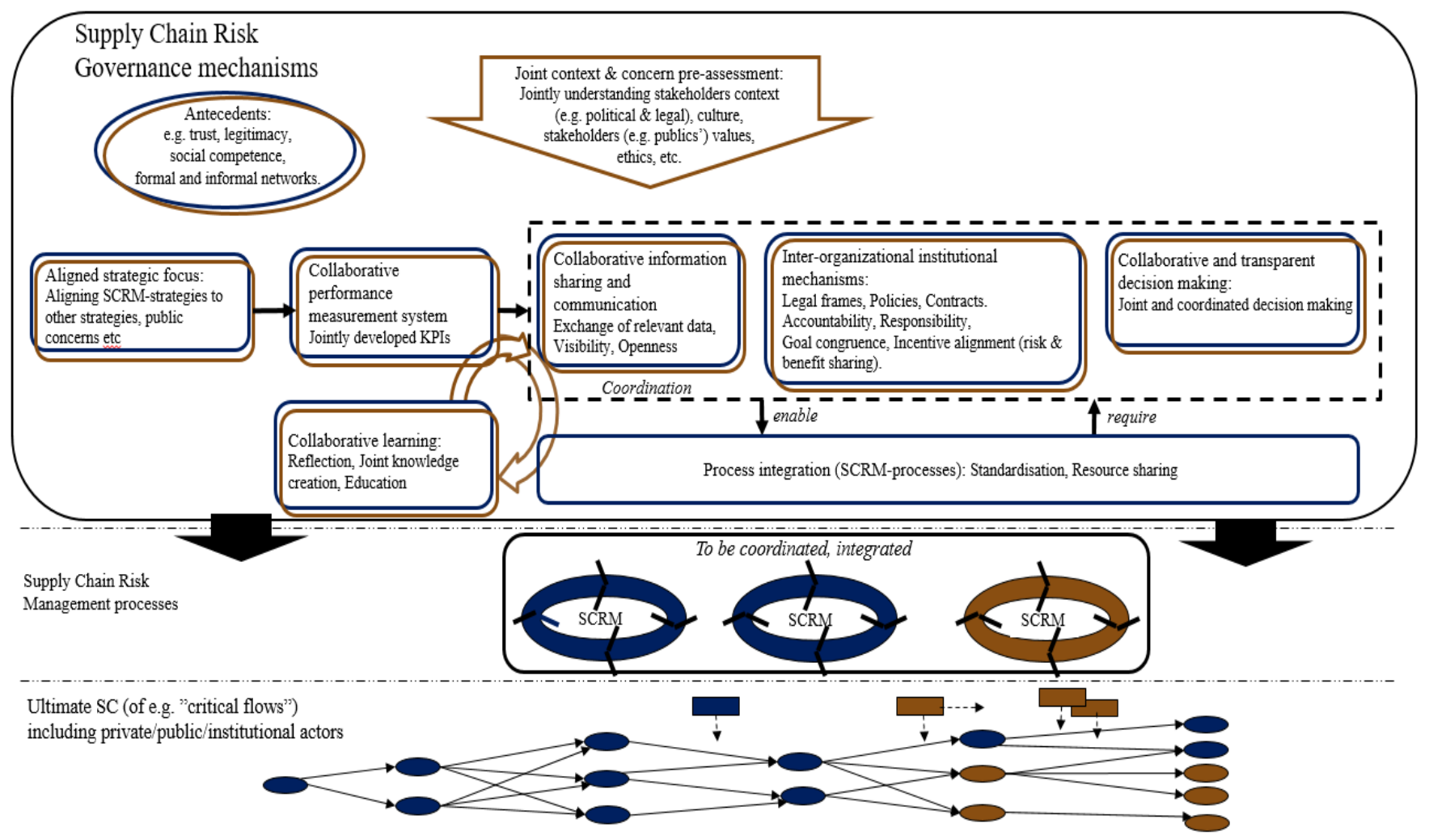

Figure 4 Conceptual multi-level framework for supply chain risk governance

The majority of the governance mechanisms illustrated in this framework are relational. Two of these mechanisms (collaborative information sharing and communication as well as collaborative and transparent decision making) should increase collaboration and coordination (Simatupang and Sridharan, 2005) in parallel with the inter-organisational institutional mechanisms. First, collaborative information sharing and communication are, in both domains, proposed as important relational governance mechanisms and are characterised by openness, visibility and the exchange of relevant data (related to both critical flows and risk management processes) (Bak, 2018; Cao et al., 20109; Govindan and Chaudhuri, 2016; Li et al., 2015; van Asselt and Renn, 2011). Second, collaborative and transparent decision-making (Dubreuil, 2001; Friday et al., 2018; Sajeva and Masera, 2006) describes how joint and coordinated decision-making can be facilitated and take place both proactively and reactively. This includes the platforms that are available for coordinated decision-making. While these supply chain risk governance mechanisms should enable more integration of the previously segregated SCRM processes, it is also of interest to consider how the integrated SCRM processes could be developed and defined (Friday et al., 2018). This more operational dimension and the related practices are less discussed in the risk governance literature. The SCRM literature, however, proposes standardisation and resource sharing, for example.

At a higher level, the risk governance literature suggests the importance of having mechanisms for a joint pre-estimation of the context (Klinke and Renn, 2012; Renn, 2008; Renn et al., 2011). This could influence the aligned strategic focus in particular. The involvement of many actors with presumably different perspectives makes it important to jointly understand various stakeholders' political and legal contexts, cultures, values, ethics and so on. The public constitutes an important stakeholder as its 'votes' can be very important for other stakeholders and decision-makers, such as politicians. This type of governance mechanism is hardly discussed in the SCRM literature. The risk governance literature, creating a better joint understanding of the societal context, also contributes important antecedents for a more coordinated and joint SCRM, characterised by level of trust, legitimacy, social competence and formal and informal networks (Boholm et al., 2012; Dubreuil, 2001). Many such antecedents were also found in the SCRM literature. Finally, mechanisms for collaborative learning are important to developing and improving SCRM processes both internally and between actors (Cao et al., 20109; Dubreuil, 2001; Kache and Seuring, 2014; van Asselt and Renn, 2011). Their development could be based on experiences from both proactive and reactive SCRM work. Learning, characterised by mechanisms for reflection, joint knowledge creation and education, seems more frequently discussed in articles related to the term resilience and can be found in both domains. Although we did not identify many articles on this in our initial search, we suggest that collaborative learning is an inter-organisational governance mechanism. This governance mechanism builds on an iterative loop related to 
collaborative performance measurement, collaborative information sharing and experiences from the actual process integration.

\section{CONCLUSIONS, LIMITATIONS, AND FUTURE RESEARCH}

Many supply chains in the multi-actor, private-public partnership context face inter-organisational challenges regarding risk management. Handling the risks arising in or disrupting these supply chains requires extensive collaboration between the actors. Because these actors have different characteristics, governance mechanisms relevant to them all need to be in place. SCRM was established to address risk in supply chains consisting mainly of private companies, but that leaves a large part of society's stakeholders outside the risk appraisal. In a similar vein, research in RMSS focusing on risk governance normally neglects private supply chain flows and focuses on the highlevel context. We claim that it will be easier to design proper governance mechanisms when the underlying similarities and differences in backgrounds and perspectives are understood.

We have thus compared and combined risk governance in the RMSS domain with collaborative SCRM in a multilevel framework that includes the supply network, risk management processes and inter-organisational governance mechanisms that could drive increased collaboration in SCRM. This extends previous multi-level frameworks that do not discuss collaboration mechanisms. Further, we extend the mechanisms proposed in Simatupang and Sridharan's (2005) framework by adding societal variables, such as policies and legal frameworks, as well as learning, contextual pre-assessment and antecedents. Our multi-level framework contributes a new set of governance mechanisms that future research should empirically test on diverse types of supply chains. To do this, the governance mechanisms as well as their potential effects must be further operationalised. Another interesting matter is the question of which mechanisms function well in normal situations, in times of crisis and in transitions from normal to crisis and back again. Future empirical research could also explore whether and how national cultures impact the effects of various governance mechanisms.

This study aimed to lay the groundwork for future research in the field and to explore the possibilities offered by interdisciplinary research across these domains. The ambition was to compare important concepts and develop a tentative framework. Some articles (e.g., Friday et al., 2018; Peck, 2005; Simatupang and Sridharan, 2005; van Asselt and Renn, 2011) were more influential than others. Additionally, the literature review was more of a scoping study than a systematic literature review (see, e.g., Durach et al., 2017). Future research should complement this work especially by extending the SCRM review, thus increasing its validity. At time of printing the world has been hit by the coronavirus to an extent we could never have imagined. We hope to have contributed with a framework that will support crossdisciplinary efforts and learning, thus improving supply chain risk governance for critical infrastructures.

\section{ACKNOWLEDGEMENTS}

This project was partially supported by the European Union's Horizon 2020 Research and Innovation Programme RISE under grant agreement no. 823759 (REMESH). The authors also wish to acknowledge the civil contingency agency of Sweden (MSB) for its financial support of the cross-disciplinary project CRITFLOWS, which integrates knowledge from political science, SCM and RMSS.

\section{REFERENCES}

Adebola, M. A., Anosike, A., Garza-Reyes, J. A., and Al-Talib, M. (2018). Supply chain risk perception: Understanding the gap between theory and practice, 16 th IFAC Synopsium on Information Control Problems in Manufacturing, BergamoItaly, pp. 1701-1706.

Amor, R. B., and Ghorbel, A. (2018). The risk in Petroleum Supply Chain: A review and typology, International Journal of Scientific and Engineering Research 9 (2), pp. 141-163.

Arksey, H., and O'Malley, L. (2005). Scoping studies: towards a methodological framework. International Journal of Social Research Methodology 8 (1), pp.19-32.

Arvidsson, B., and Cedergren, A. (2016), Case studies of risk governance - a literature review. 26 ${ }^{\text {th }}$ European Safety and Reliability Conference ESREL 2016, Glasgow, United Kingdom, pp. 1231-1238.

Aven, T. (2011). On risk governance deficits. Safety Science 49 (6), pp. 912-919.

Bak, O. (2018). Supply chain risk management research agenda: From literature review to a call for future research directions. Business Process Management Journal 24 (2), pp. 567-588.

Bekkers, V., and Thaens, M. (2005). Interconnected networks and the governance of risk and trust. Information Polity: The International journal of Government \& Democracy $10(1,2)$, pp. 37-48.

Bevir, M. (2012), Governance: A very short introduction, UK: Oxford University Press, Oxford.

Boholm, A., and Corvallec, H. (2011). A relational theory of risk. Journal of Risk Research 14 (2), pp. 175-190.

Boholm Å., Corvellec H., and Karlsson M. (2012). The practice of risk governance: lessons from the field. Journal of Risk Research 15 (1), pp. 1-20.

Brown, L., and Osborne, S. P. (2013). Risk and innovationTowards a framework for risk governance in public services. Public Management Review 15 (2), pp. 186-208.

Cantor, D. E., Blackhurst, J., Pan, M., and Crum, M. (2014). Examining the role of stakeholder pressure and knowledge management on supply chain risk and demand responsiveness. The International Journal of Logistics Management 25 (1), pp. 202-223.

Cao, M., Vonderembse, M. A., Zhang, Q., and Ragu-Nathan, T.S. (2010). Supply chain collaboration: conceptualisation and instrument development. International Journal of Production Research 48 (22), pp. 6613-6635.

Cedergren, A., and Tehler, H. (2014). Studying risk governance using a design perspective. Safety Science 68, pp. 89-98.

Chen, J., Sohal, A. S., and Prajogo, D. I. (2013). Supply chain operational risk mitigation: a collaborative approach. International Journal of Production Research 51 (7), pp. 2186-2199.

Cruz, J. M., and Liu, Z. (2011). Modeling and analysis of the multiperiod effects of social relationship on supply chain networks. European Journal of Operational Research 214 (1), pp. 39-52.

Davis, K., Drey, N., and Gould, D. (2009). What are scoping studies? A review of the nursing literature. International Journal of Nursing Studies 46 (10), pp. 1386-1400. 
Dekker, H. C. (2004). Control of inter-organizational relationships: evidence on appropriation concerns and coordination requirements. Accounting, Organisations and Society 29 (1), pp. 27-49.

De Vries, G., Verhoeven, I., and Boeckhout, M. (2011). Taming uncertainty: the WRR approach to risk governance. Journal of Risk Research 14 (4), pp. 485-499.

DN (2020). På innsiden av Norges globale jakt på smittevernutstyr, Osman Kibar in DN Magasinet, March 23, accessed April 8 at:

https://www.dn.no/magasinet/teknologi/koronaviruset/cat hrine-m-lofthus/helse-sor-ost-rhf/pa-innsiden-av-norgesglobale-jakt-pa-smittevernutstyr/2-1-779274

Dubreuil, G. H. (2001). Present challenges to risk governance. Journal of Hazardous Materials 86 (1-3), pp. 245-248.

Dubreuil, G. H., Bengtsson, G., Bourrelier, P. H., Foster, R., Gadbois, S., Kelly, G.N., Lebessis, N., Lochard, J., and Pape, R. (2002). A report of TRUSTNET on risk governance lessons learned. Journal of Risk Research 5 (1), pp. 83- 95.

Durach, C.F, Kembro, J., and Wieland, A. (2017). A New Paradigm for Systematic Literature Reviews in Supply Chain Management. Journal of Supply Chain Management 53 (4), pp. 67-85.

Eisenhardt, K.M. (1985). Control: organizational and economic approaches. Management Science 31 (2), pp. 134-149.

Escuder-Bueno, I., and Halpin, E. (2018). Overcoming failure in infrastructure risk governance implementation: large dams journey. Journal of Risk Research 21 (11), pp. 1313-1330.

Fan, Y., and Stevenson, M. (2018). A review of supply chain risk management: definition, theory, and research agenda. International Journal of Physical Distribution \& Logistics Management 48 (3), pp. 205-230.

Ferguson, R.J., Paulin, M., and Bergeron, J. (2005). Contractual Governance, Relational Governance, and the Performance of Interfirm Service Exchanges: The Influence of BoundarySpanner Closeness. Journal of the Academy of Marketing Science 33 (2), pp. 217-234.

Florin, M. V. (2013). IRGC's approach to emerging risks. Journal of Risk Research 16 (3-4), pp. 315-322.

Friday, D., Ryan, S., Sridharan, R., and Collins, D. (2018). Collaborative risk management: a systematic literature review. International Journal of Physical Distribution \& Logistics Management 48 (3), pp. 231-253.

Ghadge, A., Dani, S., Ojha, R., and Caldwell, N. (2017). Using risk sharing contracts for supply chain risk mitigation: A buyersupplier power and dependence perspective. Computer \& Industrial Engineering 103, pp. 262-270.

Gheorghe, A. V., Masera, M., de Vries, L., Weijnen, M., and Kröger, W. (2007). Critical infrastructures: the need for international risk governance. International Journal Critical Infrastructures 3 (1-2), pp. 3-19.

Ghosh, A., and Fedorowics, J. (2008). The role of trust in supply chain governance. Business Process Management Journal 14 (4), pp. $453-470$.

Govindan, K., and Chaudhuri, A. (2016). Interrelationships of risks faced by third party logistics service providers: A DEMATEL based approach. Transportation Research Part E: Logistics and Transportation Review 90, pp. 177-195.

Grötsch, V.M., Blome, C., and Schleper, M.C. (2013). Antecedents of proactive supply chain risk management - a contingency theory perspective. International Journal of Production Research 51 (1), pp. 2842-2867.

Hanssen, L., Devilee, J., Hermans, M., van Zijverden, M., and van Asslet. M. (2018). The Use of Risk Governance Principles in Practice: Lessons from a Dutch public Institute for Risk Research and Assessment. European Journal of Risk Regulation 9 (4), pp. 632-640.
Ho, W., Zheng, T., Yildiz, H., and Talluri, S. (2015). Supply chain risk management: a literature review. International Journal of Production Research 53 (16), pp. 5031-5069.

Hoetker, G., and Mellewigt, T. (2009). Choice and performance of governance mechanisms: matching alliance governance to asset type. Strategic Management Journal 30 (10), pp. $1025-1044$.

Hufty, M. (2011). Investigating Policy Processes: The Governance Analytical Framework (GAF). In: Wiesmann, U., Hurni, H., et al. eds. Research for Sustainable Development: Foundations, Experiences, and Perspectives, Geographica Bernensia, Bern pp. 403-424.

Jüttner, U., Peck, H., and Christopher, M. (2003). Supply chain risk management: outlining an agenda for future research. International Journal of Logistics: Research and applications 6 (4), pp. 197-210.

Kache, F., and Seuring, S. (2014). Linking collaboration and integration to risk and performance in supply chains via a review of literature reviews. Supply Chain Management: An International Journal 19 (5/6), pp. 664-682.

Keasey, K., Thompson, S., and Wright, M. (2005), Corporate Governance: Accountability, Enterprise and International Comparisons, John Wiley \& Sons Ltd, England.

Kilubi, I., and Rogers, H. (2018). Bridging the gap between supply chain risk management and strategic technology partnering capabilities: insights from social capital theory. Supply Chain Management: An international Journal 23 (4), pp. 278-292.

Klinke, A., and Renn, O. (2012). Adaptive and integrative governance on risk and uncertainty. Journal of Risk Research 15 (3), pp. 273-292.

Lansink, A. O., Schut, M., Kamanda, J., and Klerkx, L. (2018). A multi-level and multi-actor approach to risk governance: a conceptual framework to support policy development for Ambrosia weed control. Journal of Risk Research 21 (6), pp. 780-799.

Lavastre, O., Gunasekaran, A., and Spalazani, A. (2014). Effect of firm characteristics, supplier relationships and techniques used on supply chain risk management (SCRM): an empirical investigation on French industrial firms. International Journal of Production Research 52 (11), pp. 3381-3403.

Lavastre, O., Gunasekaran, A., and Spalazani, A. (2012). Supply chain risk management in French companies. Decision Support Systems 52, pp. 828-838.

Li, G., Fan, H., Lee, P. K. C., and Cheng, T. C. E. (2015). Joint supply chain risk management: An agency and collaboration perspective. International Journal of Production Economics, 164, pp. 83-94.

Lindskog, R., and Sjödin, D. (2016). Risk governance through professional expertise. Forestry consultants' handling of uncertainties after a storm disaster. Journal of Risk Research 19 (10), pp. 1275-1290.

Lindskog, R., Uggla, Y., and Soneryd, L. (2011). Making Transboundary Risks Governable: Reducing Complexity, Constructing Spatial Identity and Ascribing Capabilities. AMBIO A journal of the human environment 40, pp. 111-120.

Lindøe, P. H., and Kringen, J. (2015). Risk governance of hazardous industrial ports and areas: a case study of industrial areas and harbors in Norway. Journal of Risk Research 18 (7), pp. 931-946.

Mangan, J., and Lalwani, C. L. (2016). Global Logistics and Supply Chain Management, John Wiley \& Sons Ltd, United Kingdom.

Manuj I., and Mentzer J. (2008). Global supply chain risk management. Journal of Business Logistics 29 (1), pp. 133 155 .

Martinez, J.I., and Jarillo, J.C. (1989). The Evolution of Research on Coordination Mechanisms in Multinational Corporations. Journal of International Business Studies 20 (3) pp. 489-514. 
Mays, N., Roberts, E., and Popay, J. (2001). Synthesising research evidence. In Fulop, N., Allen, P., Clarke, A., and Black, N. (Eds.), Studying the Organisation and Delivery of Health Services: Research Methods. Routledge, London.

Mentzer, J. T., DeWitt, W., Keebler, J. S., Min, S., Nix, N. W., Smith, C. D., and Zacharia, Z. G. (2001). Defining supply chain management. Journal of Business Logistics 22 (2), pp. $1-25$.

Norrman, A., and Jansson, U. (2004). Ericsson’s proactive supply chain risk management approach after a serious sub-supplier accident. International Journal of Physical Distribution \& Logistics Management 34 (5), pp. 434-456.

Norrman, A., and Naslund, D. (2019) Supply Chain Incentive Alignment: The Gap between Perceived Importance and Actual Practice. Operations and Supply Chain Management: An International Journal 12 (3), pp.129-142.

Ojala, M., and Hallikas, J. (2005). Investment decision-making in supplier networks: Management of risk. International Journal of Production Economics 104 (1), pp. 201-213.

Ouyang M. (2014). Review on modelling and simulation of interdependent critical infrastructure systems. Reliability Engineering \& System Safety 121, pp. 43-60.

Peck, H. (2005). Drivers of supply chain vulnerability: an integrated framework. International Journal of Physical Distribution \& Logistics Management 35 (4), pp. 210-232.

Poppo, L., and Zenger, T. (2002). Do formal contracts and relational governance function as substitutes or complements ? Strategic Management Journal 23 (8), pp. 707-725.

Renn, O. (2008). White paper on risk governance. Toward an integrative framework. In: Renn, O., and Walker, K.D. (eds) Global Risk Governance, International Risk Governance Bookseries, vol 1. Springer, Dordrecht.

Renn, O., Klinke, A., and van Asselt, M. (2011). Coping with Complexity, Uncertainty and Ambiguity in Risk Governance: A Synthesis. AMBIO A journal of the human environment 40, pp. 231-346.

Revilla, E., Saenz, M. J., (2017). The impact of risk management on the frequency of supply chain disruptions - A configurational approach. International Journal of Operations \& Production Management 37(5), pp. 557-576.

Rübing, P. (2012). The Changing Face of Risk Governance: Moving from Precaution to Smarter Regulation. European Journal of Risk Regulation 3 (2), pp. 145-146.

Rinaldi, S. M., Peerenboom, J. P., and Kelly, T. K. (2001). Identifying, understanding and analyzing critical infrastructure interdependencies. IEEE Control System Magazine 21 (6), pp. 11-25.

Rooderijs, J. C. M., Krassij-Dirkzwager M. M., van den Kerkhof, J. H. T. C., and Runhaar, H. A. C. (2014). Risk governance for infectious diseases: exploring the feasibility and added value of the IRGC-framework for Dutch infectious disease control. Journal of Risk Research 17 (9), pp. 1161-1182.

Rowley J., and Slack F. (2004). Conducting a literature review. Management Research News 27 (6), pp. 31-39.

Sajeva, M., and Masera, M. (2006). A strategic approach to risk governance of critical infrastructures. International Journal of Critical Infrastructures 2 (4), pp. 379-395.

Seuring S., and Gold S. (2012). Conducting content-analysis based literature reviews in supply chain management. Supply Chain Management: An international Journal 17 (5), pp. 544-555.

Simatupang, T.M., and Sridharan, R. (2005). Supply chain discontent. Business Process Management Journal 11 (4), pp. $349-369$.

Stone, V., Führ, M., Feindt, P. H., Bouwmeester, H., Linkov, I., Sabella, S., Murphy, F., Bizer, K., Tran, L., Ågerstrand, M.,
Fito, C., Andersen, T., Anderson, D., Bergamaschi, E., Cherrie, J. W., Cowan, S., Dalemcourt, J. F., Faure, M., Gabbert, S., Gajewicz, A., Fernandes, T. F., Hristozov, D., Johnston, H. J., Lansdown, T. C., Linder, S., Marvin, H. J. P., Mullins, M., Purnhagen, K., Puzyn, T., Jimenez, A. S., ScottFordsmand, J. J., Streftaris, G., van Tongeren, M., Voelcker, N. H., Voyiatzis, G., Yannopoulos, S. N., and Poortvliet, P. M. (2018). The Essential Elements of a Risk Governance Framework for Current and Future Nanotechnologies. Risk Analysis 38 (7), pp. 1321-1331.

Strange, R., Filatotchev, I., Buck, T. and Wright, M. (2009). Corporate governance and international business. Management International Review, 49 (4), pp. 395-407.

Tehler, H. (2012). Risk Governance - Understanding the management of risk in cities and regions. Training Regions Professional Paper 1 (2), pp. 1-7.

Urciuoli, L., Mohanty, S., Hintsa, J., and Boekesteijn, E. G. (2014). The resilience of energy supply chains: a multiple case study approach on oil and gas supply cains in Europe. Supply Chain Management: An International Journal 19 (1), pp.46-63.

Van Asselt M., and Renn O. (2011). Risk Governance. Journal of Risk Research 14 (4), pp. 431-449.

Van Asselt, M., and van Bree, L. (2011). Uncertainty, precaution and risk governance. Journal of Risk Research 14(4), pp. 401408 .

Van Asselt, M., Vos, E., and Wildhaber, I. (2015). Some Reflections on EU Governance of Critical Infrastructure Risks. European Journal of Risk Regulation 6 (2), pp. 185 190.

Van der Vegt, R.G., (2018a). A literature review on the relationship between risk governance and public engagement in relation to complex environmental issues. Journal of Risk Research 21 (11), pp. 1-18.

Van der Vegt, R. G. (2018b). Risk Assessment and Risk Governance of Liquefied Natural Gas Development in Gladstone, Australia. Risk Analysis 38 (9), pp. 1830-1846.

Wachinger, G., Renn, O., Begg, C., and Kuhlicke, C. (2013). The Risk Perception Paradox - Implications for Governance and Communication of Natural Hazards. Risk Analysis 33 (6), pp. 1049-1065.

Wathne, K.H. and Heide, J.B. (2004). Relationship Governance in a Supply Chain Network. Journal of Marketing 68, pp.73-89.

Wieland, A., and Wallenberg, C. M. (2013). The influence of relational competencies on supply chain resilience: a relational view. International Journal of Physical Distribution \& Logistics Management 43 (4), pp. 300-320.

Williamson, O. E. (1979). Transaction-Cost Economics: The Governance of Contractual Relations. Journal of Law and Economics 22 (2) pp. 233-261.

Wong, C. M. L. (2015). The Mutable nature of risk and acceptability: A hybrid risk governance framework. Risk Analysis 35 (11), pp. 1969-1982.

Ying, K. T., Chung, S.H., and Kulwant, S. P. (2018). Risk perception and decision making in the supply chain: theory and practice, Industrial Management \& Data Systems 118 (7), pp. 1322-1326.

Zeng, B., and Yen, B. P. C. (2017). Rethinking the role of partnership in global supply chains: a risk-based perspective. International Journal of Production Economics 185, pp. 5262.

Zhu, Q., Krikke, H., and Caniëls, M. C. J. (2017). Integrated supply chain risk management: a systematic review. The International Journal of Logistics Management 28 (4), pp. $1123-1141$

Victoria Ahlqvist is a $\mathrm{PhD}$ student at Lund University, Faculty of Engineering, Sweden. She has a MSc in Industrial Engineering and Management from Lund University with a specialisation in supply chain management. Ahlqvist wrote her master thesis on construction logistics and has previously worked as a health and security manager and production engineer at 
a large construction company. Her current research interests are in supply chain risk management and governance as well as emergency supply chains and critical infrastructure flows.

Andreas Norrman is Professor in Supply chain structure and organization at Lund University, Faculty of Engineering, Sweden. He has a Ph.D. in logistics from Linköping University, Sweden. Andreas has worked as a management consultant at A.T.Kearney with supply chain management and sourcing issues. His research interests include Supply chain risk management, Supply chain incentive alignment, Omni-channel warehousing, Change management and Blockchain. He publishes in leading logistics journal and he received multiple Emerald Highly Commended Awards for his work with IJPD\&LM, both as author and reviewer. Fifteen years ago, he authored the article "Ericsson's proactive supply chain risk management approach after a serious sub-supplier accident" which became one of the most cited articles in SCRM. At Lund University he has been awarded Excellent Teaching Practice.

Marianne Jahre is Professor of Logistics at Lund University and BI Norwegian Business School. She has co-edited and coauthored several books and published articles among others in JOM, IJDPLM, JHLSCM, IJL: R\&A and IJLM. Jahre has been working with disaster relief logistics research and teaching since 2007, heading projects and supervising students undertaken in cooperation with IFRC, UNHCR, UNFPA, UNICEF, Norwegian Red Cross, and the Norwegian Refugee Council. She is an international delegate to the Norwegian Red Cross and undertook projects on health supply chains in Uganda for UNICEF. She now heads a mobility project in cooperation with Jimma University in Ethiopia, leads a research project on drug shortage in cooperation with the Norwegian Institute of Public Health and 3 other universities. 